\title{
Tobacco use and self-reported morbidity among rural Indian adults
}

\author{
Anamitra Barik ${ }^{1,2}$, Rajesh Kumar Rai ${ }^{3}$ and Abhijit Chowdhury ${ }^{4,5}$ \\ ${ }^{1}$ Research Coordinator, Society for Health and Demographic Surveillance, Suri, Birbhum, West Bengal, India \\ ${ }^{2}$ Senior Medical Officer, Chest Clinic, Suri District Hospital and Niramoy TB Sanatorium, Suri, Birbhum, West Bengal, India \\ ${ }^{3}$ Senior Research Scientist, Society for Health and Demographic Surveillance, Suri, Birbhum, West Bengal, India \\ ${ }^{4}$ Project Director, Society for Health and Demographic Surveillance, Suri, Birbhum, West Bengal, India \\ ${ }^{5}$ Professor \& Head, Department of Hepatology, School of Digestive and Liver Diseases, Institute of Post Graduate Medical \\ Education and Research (IPGMER), Kolkata, India
}

\begin{abstract}
Aim: To measure the prevalence of self-reported morbidity and its associated factors among adults (aged $\geqslant 15$ years) in a select rural Indian population. Background: Selfreporting of smoking has been validated as population-based surveys using self-reported data provide reasonably consistent estimates of smoking prevalence, and are generally considered to be sufficiently accurate for tracking the general pattern of morbidity associated with tobacco use in populations. However, to gauge the true disease burden using self-reported morbidity data requires cautious interpretation. Methods: During 20102011, a cross-sectional survey was conducted under the banner of the Health and Demographic Surveillance System, Birbhum, an initiative of the Department of Health and Family Welfare, Government of West Bengal, India. With over 93.6\% response rate from the population living in 12300 households, this study uses the responses from 16354 individuals: 8012 smokers, and 8333 smokeless tobacco users. Smokers and smokeless tobacco users were asked whether they have developed any morbidity symptoms due to smoking, or smokeless tobacco use. Bivariate, as well as multivariate logistic regression analyses were deployed to attain the study objective. Findings: Over $20 \%$ of smokers and over $9 \%$ of smokeless tobacco users reported any morbidity. Odds ratio (OR) with $95 \%$ confidence interval $(\mathrm{Cl})$ estimated using logistic regression shows that women are less likely to report any morbidity attributable to smoking (OR: $0.69 ; \mathrm{Cl}: 0.54-0.87$ ), and more likely to report any morbidity due to smokeless tobacco use (OR: 1.68; $\mathrm{Cl}$ : 1.36-2.09). Non-Hindus have higher odds, whereas the wealthiest respondents have lower odds of reporting any morbidity. With a culturally appropriate intervention to change behaviour, youth (both men and women) could be targeted with comprehensive tobacco cessation assistance programmes. A focussed intervention could be designed for unprocessed tobacco users to curb hazardous effects of tobacco use.
\end{abstract}

Key words: India; morbidity; non-communicable diseases; smoking; Tobacco

Received 17 November 2015; revised 26 February 2016; accepted 29 March 2016; first published online 21 April 2016

\section{Introduction}

Tobacco consumption is currently the single leading preventable cause of death globally, and it is projected that over 500 million people may die due to tobacco by 2030 (World Health Organization, 2013). Among the recently unveiled Sustainable Development Goals, endorsed by

Correspondence to: Rajesh Kumar Rai, Senior Research Scientist, Society for Health and Demographic Surveillance Suri, Birbhum 731101, West Bengal, India. Email: rajesh.iips28@gmail.com 
193 countries in September 2015, target 3 commits to 'strengthen the implementation of the World Health Organization Framework Convention on Tobacco Control in all countries'. Over 1.1 billion smokers reside in low and middle income countries where tobacco consumption is on the rise, in contrast to declining consumption in high-income countries (Gajalakshmi et al., 2000). With a population of over 1.25 billion, India accounts for an unacceptably high incidence of tobacco use. In 2000, 1.1 million deaths were attributed to tobacco use in the South East Asian region, and $62 \%$ of all deaths were in India (Ezzati and Lopez, 2004). In this region, the production of cigarettes has increased by more than $50 \%$ between 1993 and 2003 , thus the increase in burden of tobaccorelated diseases (Shafey et al., 2003). The National Action Plan and Monitoring Framework for Prevention and Control of NCDs in India developed by the Ministry of Health and Family Welfare aims to reduce prevalence of tobacco use by $15 \%$ by the year 2020 and $30 \%$ by the year 2025 (Government of India, 2014). The additional increased burden of liver cancer, colorectal cancer, cardiovascular disease morbidity, and diabetes cases attributed to smoking mean the number of serious medical conditions caused by smoking could be much larger (WHO Framework Convention on Tobacco Control, 2014).

About $19 \%$ of tobacco consumption in India is in the form of cigarettes, while $53 \%$ is smoked as bidis [sun-dried and processed tobacco flakes, rolled in a tendu leaf (Diospyros Elanoxylon) or temburni leaf and held together by a cotton thread] (Gupta and Asma, 2008). Overall, smoking is estimated to increase the risk for coronary heart disease by two to four times, for stroke by two to four times, and of developing lung cancer by over 25 times (US Department of Health and Human Services, 2014). Smokers at greater risk of developing cardiovascular disease are also at increased risk of lung diseases caused by smoking, including chronic obstructive pulmonary disease (COPD) (US Department of Health and Human Services, 2014). In addition, smoking could cause cancer almost anywhere in your body - bladder, blood (acute myeloid leukaemia), cervix, colorectal, oesophagus, kidney and ureter, larynx, liver, oropharynx, pancreas, stomach, trachea, bronchus, and lung (US Department of Health and Human Services, 2014). The 'poor man's cigarette', the bidi, has relatively low combustibility and the nonporous nature of the tendu leaves requires more frequent and deeper puffs by the smoker to keep bidis lit, and is therefore harder on the smoker's lungs than cigarettes rolled in paper. Bidis produce approximately three times the amount of carbon monoxide and nicotine, and approximately five times the amount of tar as cigarettes (Gupta and Asma, 2008).

On the other hand, use of smokeless tobacco, including chewing, snuffing, sucking, rubbing on the teeth and placing on the gum, have been a part of the culture in South and South East Asian countries (Sorensen et al., 2005; Piano et al., 2010; Stanfill et al., 2011). In these countries, smokeless tobacco is commonly used by those with low education, the unemployed and unskilled workers (Sorensen et al., 2005). In India, over $25 \%$ of tobacco users consume smokeless tobacco (Gupta and Asma, 2008). For the smokeless tobacco users, teeth and gums are the most vulnerable areas, causing discoloration of teeth and requiring dental restorations and dentures (Asmussenand Hansen, 1986). A possible lower salivary $\mathrm{pH}$ and buffering power, and the shift of the bacterial population towards lactobacillus and cariogenic streptococci, lead to dental caries among smokeless tobacco users (Heintze, 1984; Parvinen, 1984).

Self-reported smoking and its related morbidity remain debated in the international tobacco research arena. Some studies argue that reliance on self-reported smoking leads to underestimation of prevalence and could potentially mislead the intervention required for cessation (Shipton et al., 2009). Self-reported measures of morbidity in developing countries have been viewed with considerable scepticism because these measures of morbidity are misleading (Subramanian et al., 2009) According to Sen (2002) an individual assessment of health is directly contingent on the social experience, and this leads to less reporting of illness among socially disadvantaged people as they fail to perceive the presence of health deficits. The lack of health knowledge and different health beliefs have been considered to be the main reasons for less reporting of morbidity.

On the other hand, self-reporting of smoking has been validated as population-based surveys using self-reported data provide reasonably consistent estimates of smoking prevalence, and are generally considered to be sufficiently accurate for 
tracking the general pattern of tobacco use in populations (US Department of Health and Human Services, 2014). Self-reported tobacco (smoking and smokeless) attributable morbidity was tested to be reliable in developed countries such as the United States (Klebanoff, 1998), and developing countries such as India (Rani et al., 2003; Barik et al., 2015). Although self-reported morbidity helps to gauge the level of perceived morbidity, which could be helpful in designing behavioural change interventions, to gauge the true disease burden using self-reported morbidity data requires cautious interpretation. Bearing this caution in mind, this study uses the data from a Health and Demographic Surveillance System, Birbhum (HDSS-BIRPOP) to understand the prevalence and associated factors of self-reported morbidity among a selected rural Indian adult population. Findings from this study may help design interventions to reduce the level of tobacco use, a leading cause of non-communicable diseases among the adult Indian population.

\section{Methods}

\section{Data set}

Data for the present study were drawn from the Birbhum Population Project (BIRPOP), a Health and Demographic Surveillance System (HDSS) site in West Bengal, a state located along the eastern boundary of India (Ghosh et al., 2015). Birbhum (one of 19 districts of West Bengal) is predominantly rural in character and listed as backward from its ranking in socio-demographic and human development indicators. The HDSS-BIRPOP site covers four of 19 blocks of Birbhum, namely Mohammad Bazar, Rajnagar, Sainthia, and Suri I. The HDSS-BIRPOP gathers information on demographic processes, population health and epidemiology, and healthcare utilization, in its well-defined cohort population. At its inception in 2008, the 2001 Census was used as the sampling frame to select the study population. By adopting a multi-stage sampling design, 12300 self-weighted households were sampled taking into account a $10 \%$ drop out and non-participation rate. More about the sampling procedure and the cohort profile of HDSS-BIRPOP can be obtained from the HDSSBIRPOP's published report (Society for Health and Demographic Surveillance, 2013) as well as journal articles (Ghosh et al., 2015).

With over $93.6 \%$ response rate from the population living in 12300 households, this study uses the responses from 16354 (8021 smokers, and 8333 smokeless tobacco users) individuals (aged $\geqslant 15$ years) to fulfil the study objective. Between October 2010 and January 2011, the survey was conducted by 44 trained interviewers having at least an undergraduate degree and some exposure to large-scale sample surveys. All the interviewers (designated as the Surveyors in HDSS-BIRPOP) were native speakers of at least one of the local languages - Bengali and Santhal (tribal language).

\section{Defining self-reported morbidity}

Before launching the full-fledged project on smoking behaviour, SHDS-BIRPOP ran a pilot survey among $10 \%$ of households to gauge the type of self-reported morbidity due to smoking and smokeless tobacco use. The questions on the type of morbidity were framed accordingly in the main survey. To gather the information on self-reported morbidity separately, smokers as well as smokeless tobacco users were asked whether they have developed any morbidity symptoms due to smoking, or smokeless tobacco use. If they responded positively, they were asked to list those symptoms. The symptoms perceived to be attributable to certain morbidity are listed in Table 1. Currents smokers were people smoking cigarette, bidi, chilum, and/or hooka, whereas current smokeless tobacco users were chewing paan masala, betel quid, khaini, gutkha, guraku, or other forms of smokeless tobacco (eg, snuff). Respondents are considered to be current users if tobacco is consumed in any form within last 30 days of the survey date.

\section{Covariates}

This study aims to determine the predictors associated with self-reported morbidity. The selected variables are frequency of tobacco use (categorized as often, 1-5 times per day, 6-10 times per day, >10 times per day); age; sex (categorized as men and women); religion (categorized as Hindu and Non-Hindu); social group (categorized as Others, Scheduled Caste, Scheduled Tribe, and Other Backward Classes); years of education (categorized as none/illiterate, 
Table 1 Percentage distribution of current tobacco users (smokers and smokeless tobacco users) by self-reported morbidity, HDSS-BIRPOP, 2010-2011

\begin{tabular}{|c|c|c|}
\hline & $\begin{array}{l}\text { Percentage } \\
\text { distribution } \\
(n)\end{array}$ & $\begin{array}{l}95 \% \text { confidence } \\
\text { interval (lower } \\
\text { limit - upper limit) }\end{array}$ \\
\hline \multicolumn{3}{|l|}{ Smokers } \\
\hline $\begin{array}{l}\text { No self-reported } \\
\text { morbidity from } \\
\text { smoking }\end{array}$ & $79.5(6377)$ & $78.8-80.5$ \\
\hline Dry cough & $8.6(690)$ & $7.7-9.0$ \\
\hline Productive cough & $4.5(361)$ & $4.1-5.0$ \\
\hline Chest pain & $3.3(265)$ & $2.9-3.7$ \\
\hline Body ache & $1.9(152)$ & $1.6-2.2$ \\
\hline Bad breath & $0.2(16)$ & $0.1-0.3$ \\
\hline Others & $2.0(160)$ & $1.7-2.3$ \\
\hline Total & $100.0(8021)$ & \\
\hline \multicolumn{3}{|l|}{ Smokeless tobacco users } \\
\hline $\begin{array}{l}\text { No self-reported } \\
\text { morbidity from } \\
\text { smokeless tobacco use }\end{array}$ & 90.7 (7558) & $90.2-91.5$ \\
\hline Mouth ulceration & $0.4(33)$ & $0.1-0.3$ \\
\hline Tongue ulceration & $0.5(42)$ & $0.4-0.7$ \\
\hline Bad breath & $0.1(8)$ & $0.1-0.2$ \\
\hline Gum infection & $0.6(50)$ & $0.4-0.8$ \\
\hline Tooth decay & $5.6(467)$ & $5.1-6.1$ \\
\hline Others & $2.1(175)$ & $1.8-2.4$ \\
\hline Total & $100.0(8333)$ & \\
\hline
\end{tabular}

1-5 years, 6-10 years, and 11 or more years); occupation (categorized as unemployed, business or service or retired, agricultural and nonagricultural labour, and agriculture); and wealth quintile (poorest, poorer, middle, richer, and richest). If the use of tobacco was irregular, it was categorized as the 'often' use of tobacco. Scheduled Castes (SC) and Scheduled Tribes (ST) are identified by the Government of India as socially and economically backward and needing protection from social injustice and exploitation. Other Backward Class (OBC) covers diverse intermediate castes that are socioeconomically more advantaged than SCs and STs. Others is thus a residual group that enjoys higher status in the social group hierarchy.

It is worth reporting that the HDSS-BIRPOP conducted a separate socioeconomic survey in 2010, parallel to the survey on tobacco consumption. Using a unique identification number, information from both surveys was merged to obtain the required socioeconomic information. To compute a composite proxy indicator of income, Principal Component Analysis (Vyas and Kumaranayake, 2006) was employed to calculate a relative index of household wealth quintile from the standard set of assets owned by the household, which included ownership of consumer items and dwelling characteristics. Individuals were ranked on the basis of their household scores and divided into different quintiles, each representing $20 \%$ of the score, between 1 (poorest) and 5 (richest). Apart from the socioeconomic variables, self-reported age and sex were also used for the analysis.

\section{Statistical analysis}

To identify the factors associated with selfreported morbidity, both bivariate and multivariate analyses were used. To be specific, bivariate analysis with a $\chi^{2}$ test was used to understand the proportional difference in reporting morbidity. To understand the net effect of factors associated with self-reported morbidity, a binary logistic regression (Retherford and Choe, 1993) was applied. Instead of a linear probability model, a binary logistic regression function proves preferable to fit some kind of sigmoid curve when the response variable is dichotomous (binary or $0-1$ ), and it reasonably portrays the reality about outcome events (Retherford and Choe, 1993). The logistic function takes an input that can be any value from negative infinity to positive infinity, whereas the output is confined to values between 0 and 1 . In this study, the binomial responses were coded for each individual, as follows: self-reported morbidity by smokers (coded as 1) or not (coded as $0)$; self-reported morbidity by smokeless tobacco users (coded as 1) or not (coded as 0 ). These binomial responses were related to a set of predictors: frequency of tobacco use, age, sex, religion, social group, education, occupation, wealth quintile, and block of residence. Data analyses were performed using statistical software Stata version 12 (StataCorp, 2011). The variables found significant at $P<0.05$ level in the binary logistic regression model (with a single step entry of all predictor variables) are discussed in this study.

\section{Results}

Table 1 represents the percentage distribution of current tobacco users (current smokers, and 
smokeless tobacco users) by self-reported morbidity. Among current smokers, almost $9 \%$ reported experiencing dry cough attributed to smoking, followed by productive cough $(4.5 \%)$, and chest pain $(3.3 \%)$. Almost $6 \%$ of smokeless tobacco users complained of tooth decay. The selfreported morbidity due to tobacco use is estimated to be higher among smokers than smokeless tobacco consumers.

Table 2 demonstrates the statistics on distribution of smokers and smokeless tobacco users and percentage of any self-reported morbidity by their background characteristics. Over $20 \%$ of smokers and over $9 \%$ of smokeless tobacco users reported of any morbidity. There is non-significant difference in any morbidity between smokers smoking one to five times a day (22\%) and $>10$ times a day $(21 \%)$. With a higher frequency of smokeless tobacco use, the self-reported morbidity is likely to increase. With increasing age, a steady increase in any self-reported morbidity due to smoking was registered. Irrespective of type of tobacco use, women and non-Hindus were more likely to report morbidity. As compared to smokers or smokeless tobacco users from other social group, STs reported lower morbidity prevalence. Illiterate, unemployed and poorest quintile respondents estimated the highest self-reported morbidity. Of people living in Rajnagar block, nearly $31 \%$ and $29 \%$ reported of any morbidity due to smoking and smokeless tobacco use, respectively.

Table 3 represents OR with $95 \%$ CI showing the factors associated with self-reported morbidity by smokers and smokeless tobacco users. With increasing frequency of tobacco use and age, the self-reported morbidity is likely to increase. Women are less likely to report any morbidity due to smoking (OR: 0.69; CI: 0.54-0.87), and more likely to report morbidity attributed to smokeless tobacco use (OR: 1.68; CI: 1.36-2.09). Non-Hindus have higher odds of reporting any morbidity from tobacco use, whereas the richest quintile has lower odds of reporting any morbidity.

\section{Discussion}

Using data from HDSS-BIRPOP of West Bengal, India, this paper attempts to understand the prevalence of any self-reported morbidity among tobacco users, and the factors associated with it.
Over $20 \%$ of people reported any morbidity due to smoking, and over $9 \%$ of the population reported any morbidity attributable to smokeless tobacco use. Tobacco use frequency, sex, religion, and wealth quintile were estimated to have a statistically significant association with self-reported morbidity status.

Irrespective of tobacco type, with increasing frequency of tobacco use, and as age advances, people are more likely to report morbidity. Although with the increasing frequency of tobacco use, the reporting of any morbidity is intuitive; with increasing age, reporting of morbidity is consistent with studies showing smoking starts at relatively later ages in India (Jha et al., 2008). As smoking starts at an older age tobacco users are expected to experience some symptoms of smoking attributable morbidity as age advances (James, 2011). The findings also indicate that men are more likely to report any morbidity due to smoking, whereas self-reported morbidity due to smokeless tobacco use is common among women.

Gender differences in tobacco consumption are widely documented. While female rates are lower overall, substantial proportions of women smoke in some countries, and smokeless tobacco use by women often goes unreported (World Health Organization, 2011) Prevalence of smoking any tobacco product was generally much higher for men than women in India. According to the latest nationally representative survey report, almost $48 \%$ of men (aged $\geqslant 15$ years) are estimated to be currently using some form of tobacco, whereas the figure is much lower (nearly $20 \%$ ) for women of the same age group (Ram et al., 2010) Smoking instead of using smokeless tobacco is seen as masculine among men in rural India, and the prevalence of smokeless tobacco is higher among women (World Health Organization, 2011). Thus, cause of reporting of any morbidity due to smoking is higher among men compared to women, whereas women reported morbidity attributed to smokeless tobacco use. If the smoking rates continue, of the million annual deaths from smoking in India, $70 \%$ (100000 among women and 600000 among men) will occur in middle age, rather than old age (Jha et al., 2008).

The study reveals that non-Hindus are more likely to report any morbidity. In HDSS-BIRPOP, the Hindu population makes up over $70 \%$ of the total population, whereas over $29 \%$ are Muslims, 
Table 2 Total number of smokers and smokeless tobacco users and percentage of self-reported any morbidity by background characteristics, HDSS-BIRPOP, 2010-2011

\begin{tabular}{|c|c|c|c|c|}
\hline & $\begin{array}{l}\text { Total number of } \\
\text { smokers }(\%)\end{array}$ & $\begin{array}{l}\text { Morbidity } \\
(\%)\end{array}$ & $\begin{array}{l}\text { Total number of smokeless } \\
\text { tobacco users }(\%)\end{array}$ & $\begin{array}{l}\text { Morbidity } \\
(\%)\end{array}$ \\
\hline Frequency of tobacco use & & $\chi^{2}: 22.09 ; P<0.001$ & & $\chi^{2}: 28.24 ; P<0.001$ \\
\hline Often & $253(3.2)$ & 10.7 & $487(5.8)$ & 3.9 \\
\hline $1-5$ per day & 1675 (20.9) & 22.1 & $5441(65.3)$ & 9.2 \\
\hline $6-10$ per day & $2379(29.7)$ & 19.2 & $1833(22.0)$ & 9.8 \\
\hline$>10$ per day & $3714(46.3)$ & 21.4 & $572(6.9)$ & 13.3 \\
\hline Age group & & $\chi^{2}: 532.78 ; P<0.001$ & & $\chi^{2}: 59.51 ; P<0.001$ \\
\hline $15-24$ & $885(11.0)$ & 7.6 & $1412(16.9)$ & 4.7 \\
\hline $25-34$ & 1598 (19.9) & 9.3 & $1774(21.3)$ & 7.9 \\
\hline $35-44$ & $2098(26.2)$ & 17.7 & 2035 (24.4) & 11.2 \\
\hline $45-54$ & $1839(22.9)$ & 26.0 & $1499(18.0)$ & 10.9 \\
\hline $55-64$ & 1079 (13.5) & 32.5 & $973(11.7)$ & 10.1 \\
\hline$\geqslant 65$ & $522(6.5)$ & 44.3 & $640(7.7)$ & 12.2 \\
\hline Sex & & $\chi^{2}: 10.32 ; P<0.01$ & & $\chi^{2}: 22.54 ; P<0.001$ \\
\hline Men & 7477 (93.2) & 20.2 & $4746(57.0)$ & 8.0 \\
\hline Women & $544(6.8)$ & 25.9 & $3587(43.0)$ & 11.0 \\
\hline Religion & & $\chi^{2}: 19.83 ; P<0.001$ & & $\chi^{2}: 0.44 ; \mathrm{ns}$ \\
\hline Hindu & $5853(73.0)$ & 19.3 & $5630(67.6)$ & 9.1 \\
\hline Non-Hindu & $2168(27.0)$ & 23.8 & 2703 (32.4) & 9.6 \\
\hline Social group & & $\chi^{2}: 7.51 ; \mathrm{ns}$ & & $\chi^{2}: 13.60 ; P<0.01$ \\
\hline Others & 3579 (44.6) & 21.5 & $3842(46.1)$ & 9.5 \\
\hline SC & $3352(41.8)$ & 20.4 & 2825 (33.9) & 9.9 \\
\hline ST & $667(8.3)$ & 16.9 & $1211(14.5)$ & 6.5 \\
\hline $\mathrm{OBC}$ & $423(5.3)$ & 19.4 & $455(5.5)$ & 10.8 \\
\hline Education (years) & & $\chi^{2}: 88.12 ; P<0.001$ & & $\chi^{2}: 18.68 ; P<0.001$ \\
\hline None/illiterate & 3663 (45.7) & 24.5 & $4297(51.6)$ & 10.5 \\
\hline $1-5$ & $1683(21.0)$ & 20.5 & $1868(22.4)$ & 8.1 \\
\hline $6-10$ & $2082(26.0)$ & 16.3 & $1844(22.1)$ & 8.1 \\
\hline$\geqslant 11$ & $593(7.4)$ & 11.3 & $324(3.9)$ & 5.9 \\
\hline Occupation & & $\chi^{2}: 59.94 ; P<0.001$ & & $\chi^{2}: 8.79 ; P<0.05$ \\
\hline Unemployed & 1102 (13.7) & 29.0 & 3025 (36.3) & 10.3 \\
\hline Business/services/retired & $2144(26.7)$ & 18.1 & $1340(16.1)$ & 9.3 \\
\hline $\begin{array}{l}\text { Agricultural and } \\
\text { non-agricultural labour }\end{array}$ & 2476 (30.9) & 19.1 & $2217(26.6)$ & 9.0 \\
\hline Agriculture & $2299(28.7)$ & 20.4 & $1751(21.0)$ & 7.8 \\
\hline Wealth quintile & & $\chi^{2}: 81.67 ; P<0.001$ & & $\chi^{2}: 22.57 ; P<0.001$ \\
\hline Poorest & 2045 (25.5) & 25.9 & 2296 (27.6) & 11.4 \\
\hline Poorer & $1731(21.6)$ & 20.5 & $1845(22.1)$ & 8.9 \\
\hline Middle & 2159 (26.9) & 19.5 & 2145 (25.7) & 9.1 \\
\hline Richer & $940(11.7)$ & 21.1 & 1035 (12.4) & 8.0 \\
\hline Richest & $1146(14.3)$ & 12.6 & $1012(12.1)$ & 6.7 \\
\hline Block & & $\chi^{2}: 173.11 ; P<0.001$ & & $\chi^{2}: 739.07 ; P<0.001$ \\
\hline Mohammad Bazar & $2072(25.8)$ & 24.7 & $2679(32.1)$ & 8.6 \\
\hline Rajnagar & 1009 (12.6) & 30.5 & $1230(14.8)$ & 29.3 \\
\hline Sainthia & $2968(37.0)$ & 19.9 & $2575(30.9)$ & 2.8 \\
\hline Suri I & $1972(24.6)$ & 12.0 & $1849(22.2)$ & 6.0 \\
\hline Total & $8021(100.0)$ & 20.5 & $8333(100.0)$ & 9.3 \\
\hline
\end{tabular}

SC = Scheduled Castes; ST = Scheduled Tribes; OBC = Other Backward Class.

$\chi^{2}$ represents the chi-square value obtained from the chi-square test. 
Table 3 Adjusted multivariable odds ratio (OR) with 95\% confidence interval (CI) showing the association of self-reported morbidity with tobacco use and socio-economic characteristics, HDSS-BIRPOP, 2010-2011

\begin{tabular}{|c|c|c|c|c|}
\hline & \multicolumn{2}{|c|}{ Morbidity among smokers } & \multicolumn{2}{|c|}{ Morbidity among smokeless tobacco users } \\
\hline & OR & $95 \% \mathrm{Cl}$ & OR & $95 \% \mathrm{Cl}$ \\
\hline \multicolumn{5}{|l|}{ Frequency of tobacco use } \\
\hline Often (ref.) & 1.00 & & 1.00 & \\
\hline 1-5 per day & 1.92 & $(1.24-2.97)$ & 2.40 & $(1.47-3.92)$ \\
\hline $6-10$ per day & 1.60 & $(1.04-2.47)$ & 3.33 & $(2.01-5.53)$ \\
\hline$>10$ per day & 1.74 & $(1.13-2.67)$ & 4.63 & $(2.68-8.01)$ \\
\hline Age & 1.05 & $(1.05-1.06)$ & 1.02 & $(1.02-1.03)$ \\
\hline \multicolumn{5}{|l|}{ Sex } \\
\hline Men (ref.) & 1.00 & & 1.00 & \\
\hline Women & 0.69 & $(0.54-0.87)$ & 1.68 & $(1.36-2.09)$ \\
\hline \multicolumn{5}{|l|}{ Religion } \\
\hline Hindu (ref.) & 1.00 & & 1.00 & \\
\hline Non-Hindu & 1.32 & $(1.09-1.59)$ & 1.83 & $(1.42-2.37)$ \\
\hline \multicolumn{5}{|l|}{ Social group } \\
\hline Others (ref.) & 1.00 & & 1.00 & \\
\hline $\mathrm{SC}$ & 0.98 & $(0.81-1.19)$ & 1.06 & $(0.81-1.39)$ \\
\hline ST & 0.70 & $(0.54-0.93)$ & 0.78 & $(0.56-1.10)$ \\
\hline $\mathrm{OBC}$ & 0.84 & $(0.63-1.13)$ & 0.67 & $(0.46-0.98)$ \\
\hline \multicolumn{5}{|l|}{ Education (years) } \\
\hline None/illiterate (ref.) & 1.00 & & 1.00 & \\
\hline $1-5$ & 1.05 & $(0.89-1.23)$ & 0.85 & $(0.68-1.06)$ \\
\hline $6-10$ & 0.86 & $(0.72-1.03)$ & 1.11 & $(0.87-1.42)$ \\
\hline$\geqslant 11$ & 0.65 & $(0.47-0.90)$ & 0.80 & $(0.46-1.38)$ \\
\hline \multicolumn{5}{|l|}{ Occupation } \\
\hline Unemployed (ref.) & 1.00 & & 1.00 & \\
\hline Business/services/retired & 0.99 & $(0.81-1.23)$ & 1.20 & $(0.91-1.57)$ \\
\hline Agricultural and non-agricultural labour & 1.10 & $(0.89-1.35)$ & 1.20 & $(0.94-1.53)$ \\
\hline Agriculture & 1.04 & $(0.85-1.28)$ & 1.43 & $(1.09-1.88)$ \\
\hline \multicolumn{5}{|l|}{ Wealth quintile } \\
\hline Poorest (ref.) & 1.00 & & 1.00 & \\
\hline Poorer & 0.80 & $(0.68-0.95)$ & 0.97 & $(0.77-1.22)$ \\
\hline Middle & 0.79 & $(0.67-0.92)$ & 1.03 & $(0.82-1.29)$ \\
\hline Richer & 0.78 & $(0.63-0.97)$ & 0.75 & $(0.55-1.01)$ \\
\hline Richest & 0.49 & $(0.38-0.64)$ & 0.61 & $(0.43-0.86)$ \\
\hline \multicolumn{5}{|l|}{ Block } \\
\hline Mohammad Bazar (ref.) & 1.00 & & 1.00 & \\
\hline Rajnagar & 1.41 & $(1.17-1.69)$ & 5.21 & $(4.25-6.38)$ \\
\hline Sainthia & 0.81 & $(0.70-0.93)$ & 0.27 & $(0.20-0.35)$ \\
\hline Suri I & 0.45 & $(0.37-0.53)$ & 0.64 & $(0.50-0.82)$ \\
\hline
\end{tabular}

(ref.) = Reference category; SC = Scheduled Castes; ST = Scheduled Tribes; OBC = Other Backward Class.

and less than $1 \%$ is Christian. Thus, primarily nonHindu refers to the Muslim population (Ghosh et al., 2015). The government of India considers the Muslim community as often lacking socioeconomic development (Government of India, 2006) Studies have shown that poor people in rural India are more likely to use tobacco. As the study findings indicate, Muslims are more likely to report any sort of morbidity attributed to tobacco use. In addition, those who are richest are less likely to report any morbidity due to tobacco use. Studies indicate that household budgets are usually an inelastic measure of morbidity due to tobacco use (Efroymson et al., 2001). In other words, the proportion of total household disposable income devoted to buying tobacco tends to remain the same even when tobacco prices increase. The high prevalence of tobacco use in India, coupled with 
high mortality for tobacco users, which often occurs in productive middle age, can yield catastrophic effects on a substantial number of households (Esson and Leeder, 2004). Also, the richest segments have relatively lower probability of reporting any morbidity because they use processed tobacco which is less harmful than unprocessed tobacco consumed by the poor.

To conclude, a high prevalence of self-reported morbidity is indicated in the selected rural population. As men and women are equally vulnerable to morbidity due to tobacco use, a behavioural change intervention is an urgent need of the hour. Individual level intervention such as promoting tobacco cessation should be encouraged, and community level interventions could include regulating smoke-free public places and strengthening health literacy on tobacco related matters (Reddy and Gupta, 2004). The intervention module should target the young population, as they are the potentially exposed group to initiate smoking primarily due to peers. School-based programs similar to the interventions examined in 32 schools in Chennai and Delhi could be considered as an effective approach to reducing tobacco use among young people in India (Perry et al., 2009). As health is a state subject, the West Bengal government should provide accessible and affordable cessation services including access to a tobacco cessation quit-line for all tobacco users who wish to quit it, as the quitting rate in India is unacceptably low (Jha et al., 2008). Tobacco dependence treatment should be mainstreamed into the existing healthcare delivery system. A focussed intervention should be designed for people using unprocessed tobacco. Overall, the West Bengal state government could experiment with policy interventions such as taxation, comprehensive bans on advertising, and reinforcing guidelines for packaging on labelling of bidi and cigarettes (Reddy and Gupta, 2004).

\section{Limitations and way forward}

Limitations of this study should be understood in the interpretation of the results. The selfreported morbidity is a subjective phenomenon, therefore while interpreting the findings the prevalence of morbidity reported should not be confused with clinically diagnosed morbidity.
In addition, the study uses information on current users based on their recollection of the last 30 days, which could generate some errors. Tobacco use, especially smoking, is often associated with social stigma, thus systematic underreporting could lead to a social desirability bias. In future, the HDSSBIRPOP aims to collect more information on tobacco use, and its related (clinically diagnosed) morbidity and mortality pattern among the sampled cohort population.

\section{Acknowledgements}

The authors are indebted to three anonymous reviewers who helped immensely to improve the paper.

\section{Financial Support}

The work was supported by the Department of Health and Family Welfare, Government of West Bengal, India (Memo No.: HF/O/MERT/1464/ HSL (MISC)-35/2008).

\section{Conflicts of Interest}

None.

\section{Ethical Standards}

The authors assert that all procedures contributing to this work comply with the ethical standards of relevant national and institutional guidelines and with the Helsinki Declaration of 1974, as revised in 2008.

\section{References}

Asmussen, E. and Hansen, E.K. 1986: Surface discoloration of restorative resins in relation to surface softening and oral hygiene. European Journal of Oral Sciences 94, 174-77.

Barik, A., Rai, R.K., Gorain, A., Majumdar, S. and Chowdhury, A. 2015: Socio-economic disparities in tobacco consumption in rural India: evidence from a health and demographic surveillance system. Perspectives in Public Health, doi:10.1177/1757913915609947.

Efroymson, D., Ahmed, S., Townsend, J., Alam, S.M., Dey, A.R., Saha, R., Dhar, B., Sujon, A.I., Ahmed, K.U. and Rahman, O. 2001: Hungry for tobacco: an analysis of the economic impact

Primary Health Care Research \& Development 2016; 17: 514-523 
of tobacco consumption on the poor in Bangladesh. Tobacco Control 10, 212-17.

Esson, K. and Leeder, S.R. 2004: The millennium development goals and tobacco control. Geneva: World Health Organization.

Ezzati, M. and Lopez, A.D. 2004: Regional, disease specific patterns of smoking-attributable mortality in 2000. Tobacco Control 13, 388-95.

Gajalakshmi, C.K., Jha, P., Ranson, K. and Nguyen, S. 2000: Global patterns of smoking and smoking attributable mortality. In Jha, P. and Chaloupka, F.J., editors, Tobacco control in developing countries, first edition. New York: Oxford University Press, 11-39.

Ghosh, S., Barik, A., Majumder, S., Gorain, A., Mukherjee, S., Mazumdar, S., Chatterjee, K., Bhaumik, S.K., Bandyopadhyay, S.K., Satpathi, B., Majumder, P.P. and Chowdhury, A. 2015: Health \& demographic surveillance system profile: the Birbhum population project (Birbhum HDSS). International Journal of Epidemiology 44, 98-107.

Government of India. 2006: Social, economic and educational status of the Muslim community of India. Prime Minister's High level Committee.

Government of India. 2014: Economic burden of tobacco related disease in India. Ministry of health and Family Welfare, Government of India.

Gupta, P.C. and Asma, S. 2008: Bidi smoking and public health. New Delhi: Ministry of Health and Family Welfare, Government of India.

Heintze, U. 1984: Secretion rate, buffer effect and number of lactobaccilli and streptococcus mutans of whole saliva of cigarette smokers and non-smokers. European Journal of Oral Sciences 92, 294-301.

James, K.S. 2011: India's demographic change: opportunities and challenges. Science 333, 576-80.

Jha, P., Jacob, B., Gajalakshmi, V., Gupta, P.C., Dhingra, N., Kumar, R., Sinha, D.N., Dikshit, R.P., Parida, D.K., Kamadod, R., Boreham, J., Peto, R. and RGI-CGHR Investigators. 2008: A nationally representative case-control study of smoking and death in India. The New England Journal of Medicine 358, 1137-47.

Klebanoff, M.A., Levine, R.J., Clemens, J.D., DerSimonian, R. and Wilkins, D.G. 1998: Serum cotinine concentration and self-reported smoking during pregnancy. American Journal of Epidemiology 148, 259-62.

Parvinen, T. 1984: Stimulated salivary flow rate, $\mathrm{pH}$ and lactobacillus and yeast concentrations in non-smokers and smokers. European Journal of Oral Sciences 92, 315-18.

Perry, C.L., Stigler, M.H., Arora, M. and Reddy, K.S. 2009: Preventing tobacco use among young people in India: project MYTRI. American Journal of Public Health 99, 899-906.

Piano, M.R., Benowitz, N.L., Fitzgerald, G.A., Corbridge, S., Heath, J., Hahn, E., Pechacek, T.F., Howard, G. and American Heart Association Council on Cardiovascular Nursing. 2010: Impact of smokeless tobacco products on cardiovascular disease: implications for policy, prevention,

Primary Health Care Research \& Development 2016; 17: 514-523 and treatment: a policy statement from the American Heart Association. Circulation 122, 1520-44.

Ram, F., Lahiri, S., Parasuraman, S., LaduSingh, L., Paswan, B., Singh, S.K. and Das, K.C. 2010: Global Adult Tobacco Survey (GATS) India, 2009-2010. New Delhi: International Institute for Population Sciences (IIPS), Mumbai and Ministry of Health and Family Welfare, Government of India.

Rani, M., Bonu, S., Jha, P., Nguyen, S.N. and Jamjoum, L. 2003: Tobacco use in India: prevalence and predictors of smoking and chewing in a national cross sectional household survey. Tobacco Control 12, e4.

Reddy, K.S. and Gupta, P.C. 2004: Report on tobacco control in India. New Delhi: Ministry of Health and Family Welfare, Government of India.

Retherford, R.D. and Choe, M.K. 1993: Statistical models for causal analysis. New York: John Wiley and Sons. Inc.

Sen, A. 2002: Health: perception versus observation - self reported morbidity has severe limitations and can be extremely misleading. British Medical Journal 324, 860-61.

Shafey, O., Dolwick, S. and Guindon, G.E. 2003: The tobacco control country profiles, second edition. Atlanta: American Cancer Society, World Health Organization, International Union Against Cancer.

Shipton, D., Tappin, D.M., Vadiveloo, T., Crossley, J.A., Aitken, D.A. and Chalmers, J. 2009: Reliability of self reported smoking status by pregnant women for estimating smoking prevalence: a retrospective, cross sectional study. British Medical Journal 339, b4347.

Society for Health and Demographic Surveillance. 2013: Report of activities of the Society for Health and Demographic Surveillance. Birbhum: Society for Health and Demographic Surveillance.

Sorensen, G., Gupta, P.C. and Pednekar, M.S. 2005: Social disparities in tobacco use in Mumbai, India: the roles of occupation, education, and gender. American Journal of Public Health 95, 1003-08.

Stanfill, S.B., Connolly, G.N., Zhang, L., Jia, L.T., Henningfield, J.E., Richter, P., Lawler, T.S., Ayo-Yusuf, O.A., Ashley, D.L. and Watson, C.H. 2011: Global surveillance of oral tobacco products: total nicotine, unionised nicotine and tobacco-specific N-Nitrosamines. Tobacco Control 20, e2.

StataCorp 2011: Stata Statistical Software: Release 12. College Station, TX: StataCorp LP.

Subramanian, S.V., Subramanyam, M.A., Selvaraj, S. and Kawachi, I. 2009: Are self reports of health and morbidity in developing countries misleading? Evidence from India. Social Science and Medicine 68, 260-65.

US Department of Health and Human Services 2014: The health consequences of smoking -50 years of progress: A report of the Surgeon General. Atlanta: U.S. Department of Health and Human Services, Centers for Disease Control and Prevention, National Center for Chronic Disease 
Prevention and Health Promotion, Office on Smoking and Health.

Vyas, S. and Kumaranayake, L. 2006: Constructing socioeconomic status indices: how to use principal components analysis. Health Policy and Planning 21, 459-68.

WHO Framework Convention on Tobacco Control 2014: Global progress report on implementation of the WHO framework convention on tobacco control. Geneva: World Health Organization.

World Health Organization. 2011: Gender, health, tobacco, equity. Geneva: World Health Organization.

World Health Organization. 2013: WHO report on the global tobacco epidemic 2013, enforcing bans on tobacco advertising. Geneva: World Health Organization. 